\title{
An Introduction to Conducting Quantitative K-12 Computing Education Research
}

\author{
Monica M. McGill \\ Knox College \& CSEdResearch.org \\ Galesburg, Illinois, USA \\ monica@csedresearch.org \\ Ryan Torbey \\ University of Texas at Austin \\ Austin, Texas, USA \\ ryan.torbey@utexas.edu
}

\author{
Adrienne Decker \\ University at Buffalo \\ Buffalo, New York, USA \\ adrienne@buffalo.edu \\ Rebecca Vivian \\ School of Computer Science \\ The University of Adelaide \\ Adelaide, South Australia, Australia \\ rebecca.vivian@adelaide.edu.au
}

\begin{abstract}
With the advent of computing education in primary and secondary schools, more research will be needed to determine the best way for students to learn how to think computationally and to design and develop software. As a field, computer science education researchers have been predominantly individuals who are steeped in content knowledge, but often have not had formal training in well-established educational research practices. Likewise, many also focus their research on undergraduate students in their own area of teaching. As the need for research into K-12 computing education grows, so does the opportunity for conducting quantitative studies in the field.

In this special session, the presenters will present a broad overview of how to conduct and evaluate quantitative computing education research. The presenters will spend approximately 15 minutes on each of the 4 key areas: designing a study, implementing a study and collecting data, analyzing and interpreting results, and reporting on the study. The remainder of the time will be as a question and answer period with the audience.

Since there is considerable overlap between computing education research at the primary/secondary and post-secondary levels, those new to research at the post-secondary level may also benefit from learning about form design, implementation, and reporting of research studies. Key takeaways for this session will include a basic understanding of K-12 computing education research from start to finish as well as a list of well-vetted resources to enable new researchers to explore and learn more.
\end{abstract}

\section{KEYWORDS}

Education research, study design, collecting data, reporting research, quantitative, $\mathrm{K}-12$

\footnotetext{
Permission to make digital or hard copies of part or all of this work for personal or classroom use is granted without fee provided that copies are not made or distributed for profit or commercial advantage and that copies bear this notice and the full citation on the first page. Copyrights for third-party components of this work must be honored For all other uses, contact the owner/author(s).

SIGCSE '20, March 11-14, 2020, Portland, OR, USA

(C) 2020 Copyright held by the owner/author(s).

ACM ISBN 978-1-4503-6793-6/20/03.

https://doi.org/10.1145/3328778.3366993
}

\section{ACM Reference Format:}

Monica M. McGill, Adrienne Decker, Ryan Torbey, and Rebecca Vivian. 2020. An Introduction to Conducting Quantitative K-12 Computing Education Research. In The 51st ACM Technical Symposium on Computer Science Education (SIGCSE '20), March 11-14, 2020, Portland, OR, USA. ACM, New York, NY, USA, 2 pages. https://doi.org/10.1145/3328778.3366993

\section{SUMMARY}

This session is designed to teach education research basics for researchers new to K-12 computing education research. To narrow our scope, we will focus on quantitative research and walk participants through the design, development, implementation, and reporting of a study. Since this content is rich and time is short, we view this special session as an entryway into research and will share what next steps would be for anyone interested.

It is important to note that K-12 computing education research is not limited to student participants, but can include research into any variable that can be studied in professional development, preservice teachers, and in-service teachers.

\section{OVERALL OBJECTIVE OF THE SESSION}

This hands-on, interactive and engaging special session is designed to provide a practical look at how to engage in quantitative K-12 education research in computing. Beyond an initial five-minute introduction of speakers and the importance of education research in $\mathrm{K}-12$, we will spend the subsequent 55 minutes covering each of the following topics:

- Designing a study (15 minutes),

- Implementing a study and collecting data (15 minutes),

- Analyzing and interpreting results (15 minutes), and

- Reporting on the study (10 minutes).

This will be followed by an additional 15 minutes for question and answer time with the audience.

Since time is limited, we will cover highlights in each area in step-wise fashion as well as important considerations for working with K-12 students [2]. To heighten awareness and engagement and make the session more interesting, we will provide 3 minutes at the start of each topic for the audience to work in small teams to take a set of predefined steps for that topic area given to them out of order. The teams will then work to place them in the correct 
order that they should occur. The remaining time for each topic will then be spent on discussing what happens during each step, framing it in the context that a new researcher will understand.

This session is important and relevant to the SIGCSE community due to the increased popularity of computing education in K-12 classrooms [7]. With over 55 million children expected to enter $\mathrm{K}-12$ in fall 2019 (August/September) in the United States alone, that presents remarkable and necessary research opportunities [3]. However, over the last few decades, educational research in computing has focused primarily on post-secondary students. For $\mathrm{K}-12$ computing researchers, it is important that their work be grounded in a familiarity with key research in the domain as well as the direction of policy and national/international standards [4] Additionally, as a community of researchers, we are in great need of meeting the demand for research in the K-12 area so that we can fully understand which type of curriculum works best for which particular students [6].

Not only will a special session like this give those interested a chance to learn about this type of quantitative research, we will also consider factors that will encourage them to engage in it by keeping in mind how daunting this can be to someone new. Given the amount of research on self-efficacy and the importance of building that into training programs, we will also do the same so participants will feel that they are not only welcome in this space, but they have the ability to conduct this research [1].

\section{OUTLINE OF THE SESSION}

Each section after the introduction and before the wrap-up will start with a small interactive exercise to be completed in teams.

- Introduction (5 minutes)

- Why is K-12 computing education research important?

- What are the major steps in conducting quantitative research?

- Designing a study (15 minutes)

- Identifying a problem and developing a research question

- Discovering what other researchers have found

- Implementing a study and collecting data (15 minutes)

- Research ethics

- Determining what data to collect and how to collect it

- Deciding on how you will analyze the data

- Analyzing and interpreting results (15 minutes)

- Preparing your data for analysis

- Analyzing the data

- Interpreting the results in context of previous research

- Reporting on the study (10 minutes)

- Practical steps for reporting demographic data and program data on the study, including important data to report as well as finding and submitting to publication venues

- Q\&A period and Wrap-up (15 minutes)

\section{EXPECTATIONS}

The intended audience is researchers interested in, yet new to, conducting quantitative K-12 computing education research. This session will be an introduction to this topic, covering important high-level points, such as how to develop a research question and how to report the results of the study in a paper or report. At the end of this session, the audience will be well-exposed to the process and well-equipped with additional resources (like csedresearch.org). Participants will be able to consider what they've learned in the context of their own work and how to address the details of conducting their research [5]. Specific intended outcomes are that participants will walk away with:

- A clear understanding of the major components that are included in quantitative educational research

- An understanding of some of the nuances specific to K-12 computing education

- A complete set of entry-level resources to enable further learning and understanding

- An "I can do this" attitude as well as more interest in becoming a K-12 computing education researcher

\section{SUITABILITY FOR A SPECIAL SESSION}

Although this type of material could also be disseminated in a workshop format, we intend for this session to be for those more casually interested in this topic. We view this as a way to expose new researchers to some of the components of quantitative research so that in the future, if they are more interested in learning more, they could attend a workshop or engage in other on-line or inperson resources. A special session is manageable and requires a smaller time commitment by participants, thus making this the "gateway" event that we envision.

\section{ACKNOWLEDGMENTS}

This material is based upon work supported by the U.S. National Science Foundation under Grant Nos. 1625005, 1625335, 1757402, and 1745199.

\section{REFERENCES}

[1] Albert Bandura. 1994. Self-efficacy. Encyclopedia of human behavior (Vol. 4, pp. 71-81)

[2] John W Creswell. 2008. Educational research: Planning, conducting, and evaluating quantitative. Prentice Hall Upper Saddle River, NJ.

[3] National Center for Education Statistics. 2019. Back to school statistics. https: //nces.ed.gov/fastfacts/display.asp?id $=372$

[4] Katie Hendrickson. [n. d.]. A Vision for K-12 Computer Science. https://k12cs. org/a-vision-for-k-12-computer-science/

[5] Monica M. McGill and Adrienne Decker. 2017. Computer Science Education Resource Center. https://csedresearch.org

[6] Institute of Education Sciences. [n. d.]. About the WWC. Retrieved August 26, 2019 from https://ies.ed.gove/ncee/aboutus/

[7] Megan Smith. 2016. Computer Science for All. https://obamawhitehouse.archives. gov/blog/2016/01/30/computer-science-all 